\title{
Reliability and validation of the Korean Compassionate Communication Scale
}

Hae-Kyung Joa, Sook Kyoung Park ${ }^{b}$, EunJu Song ${ }^{\mathrm{c}, *}$

aDepartment of Nursing, Jeonju University, Jeonju, Jeollabuk-do 55069, the Republic of Korea

${ }^{b}$ College of Nursing, Chonbuk National University, Jeonju, Jeollabuk-do 54896, the Republic of Korea

'Department of Nursing, Wonkwang University, Iksan, Iksan 54538, the Republic of Korea

Received: 27 July 2018; Accepted: 8 November 2018; Published: 20 September 2019

Abstract: 0bjective: The aims of this study were to develop the Korean Compassionate Communication Scale and to test its validity and reliability.

Methods: The Korean Compassionate Communication Scale was developed based on English version. This study is a methodological one in its approach.

Results: The Korean version of Compassionate Communication Scale contained 20 items and was divided into three factors that explained $63.4 \%$ of the total variance. This scale demonstrated excellent convergent and discriminant validity (100\%), and criterionrelated validity (Global Interpersonal Communication Competence $r=0.494$; self-compassion: $r=0.317$ ). Internal consistency was acceptable, and Cronbach's $\alpha$ of the total items was 0.85 .

Conclusions: This study examined The Korean Compassionate Communication Scale as an appropriate measurement of communication ability for nursing practice. Therefore, this scale suggests that the developed 20 items of the Compassionate Communication Scale can be used for therapeutic relationship and nursing education.

Keywords: compassion • communication • reliability and validity • scale

(c) Shanxi Medical Periodical Press.

\section{Introduction}

Communication was evaluated from a standpoint of sociological concepts and subjective ability, and especially it should be person-centered care with psychometric properties. ${ }^{1}$ Nursing educators should intend to evaluate communication ability using indirect and direct methods, and the former represents communication scales in nursing education. ${ }^{2}$ However, there was a lack in the scales in the nursing education. ${ }^{3}$ Therefore, this study aims to develop the Korean version of the Compassionate Communication Scale. Ramos Salazar ${ }^{4}$ developed the first scale to measure the communicative properties of compassion and to understand how it is associated with social skills, as well as to determine the degree of satisfaction in a relationship. Compassionate communication can be directly observed and measured. ${ }^{5}$

Compassion was generally developed from the Buddhist psychological concept; 6 however, medical and nursing communities focused on compassion in

How to cite this article: Jo HK, Park SK, Song EJ. Reliability and validation of the Korean Compassionate Communication Scale. Front Nurs. 2019; 3: 175-182. 
communication recently ${ }^{7}$ because it not only does compassion extend to sympathy but also encompasses empathy and relationship's satisfaction. ${ }^{4}$ Also, compassion is a recognition of patients' suffering and this action can be communicated through verbal, non-verbal, or physical intervention. ${ }^{5}$ Compassionate communication truly involves acknowledging the suffering of another human; expressing care, kindness, and understanding; and withholding judgment toward a person's shortcomings. ${ }^{6}$ In the nursing, compassion can allow nurses not only to establish a therapeutic relationship with patients but also to provide high-quality care. ${ }^{8}$

Because the nursing literature on compassion lacks clarity, ${ }^{9}$ some nursing studies used even the term "compassionate care." ${ }^{10,11}$ Recently, it is the core of nursing practice and compassionate communication that will establish itself as a one indicator ${ }^{12}$ in the future. The compassionate communication scale has also been developed for the nurses working at acute ward. ${ }^{5}$ Therefore, to extend the range of usage, this study will be developed for nursing students as well as nurses.

In addition to the Compassionate Communication Scale in this study, Social Network Services (SNSs) communication and social relationships are included. Nowadays, SNSs are attracting many people, ${ }^{13}$ as new generations are using this method and a type of communication. Since many people use SNSs as new communication methods these days, it has become so popular that core characteristics have spread all over the world. ${ }^{14}$ In the future, these developing communication scales such as SNSs communicating style must be included. Thus, this scale can measure how compassion ability can be applied to the new communication method called SNS and how will these scales be different from the current communication scales.

The aims of this study were to develop Ramos Salazar's English version ${ }^{4}$ into the Korean Compassionate Communication Scale and to test its validity and reliability.

\section{Methods}

\subsection{Design}

This study is a methodological one in its approach to develop a Korean version of the Compassionate Communication Scale to examine its validity and reliability.

\subsection{Participants}

Participants in this study consisted of South Korean university students in the nursing department. To apply exploratory factor analyses (EFAs) to the construct validity, the number of participants required is a minimum of seven times of the number of items. ${ }^{15}$ The original scale of Compassionate Communication ${ }^{4}$ consists of 23 items. Taking dropouts into account, a total of 300 questionnaires were distributed. An appropriate final sample size of 267 valid questionnaires was analyzed at the end.

\subsection{Procedure}

Before the translation of the scale, we obtained permission from the author who developed the Compassionate Communication Scale and communication expert. ${ }^{4}$ The scale was translated from English to Korean by three authors who are fluent in English and have good experience in developing scales. Two authors have been working as communication educators for more than 10 years. The translated Korean version was crosschecked by two native English speakers who are fluent in Korean. The preliminary Korean version was back-translated to English by native English speakers. Finally, the translators compared the backtranslated version with the original and discussed the differences.

The Korean version of the Compassionate Communication Scale was applied to a pilot group of three undergraduate nursing students and three new nurses. These participants answered the pre-final test of the scale to identify any latent problems in translation. The students and nurses had a good understanding of each item. The final Korean version of the Compassionate Communication Scale was then completed.

\subsection{Measurements}

\subsubsection{Korean version of Compassionate Communication Scale}

We obtained permission from Ramos Salazar (2013) ${ }^{4}$ who developed the Compassionate Communication Scale. This scale was composed of a total of 23 items measured on a 5-point Likert type scale ( 1 = Never to 5 = Very Often) and three subscales: compassionate conversation, compassionate touch, and compassionate messaging.

This is a self-reported scale, and the higher the score was, the higher the level of compassionate communication was. Ramos Salazar $(2013)^{4}$ reported Cronbach's $\alpha$ on each subscale: compassionate conversation was 0.91, compassionate touch was 0.91 , and compassionate messaging was 0.88 . This study's Cronbach's a was 0.84 . 


\subsubsection{Self-Compassion Scale}

We obtained permission from two researchers who developed the original scale ${ }^{6}$ and made the Korean version ${ }^{16}$ for convergent validity. This scale had a total of 26 items, with scores ranging from 26 to 130 points. The higher the score was, the higher the level of SelfCompassion was. Cronbach's a was 0.92 in Neff's ${ }^{6}$ study and Cronbach's a was 0.91 in Jin and Lee's syudy. ${ }^{16}$ Cronbach's a was 0.81 in this study.

\subsubsection{Global Interpersonal Communication Competence Scale}

To assess convergent validity, we obtained permission from $\mathrm{Hur}^{17}$ who developed the Korean version of the Global Interpersonal Communication Competence (GICC) Scale. This scale was developed based on Rubin et al.'s ${ }^{18}$ Interpersonal Communication Competence scale. This scale had a total of 15 items, with scores ranging from 15 to 75 points. The higher the score was, the higher the level of communication competence was. Cronbach's a was 0.80 in Hur's ${ }^{17}$ study, whereas Cronbach's a was 0.87 in this study.

\subsection{Data collection and analysis}

Data were collected from June to August 2017. Data were analyzed using IBM SPSS Statistics for Windows v. 24.0 (IBM Corporation, Armonk, NY, USA).

The procedure of the analyses was as follows:

(1) The general characteristics of the participants were calculated as real numbers and percentages.

(2) Item analysis was conducted by measuring the mean, standard deviation, and inter-item correlation coefficients; this determined whether the differences in language and cultural differences were due to the translation of foreign instruments and student characteristics affected the reliability and validity of the instrument.

(3) Internal consistency reliability was tested using Cronbach's $\alpha$.

(4) The construct validity of the scale was investigated with EFA.

(5) To examine convergent and discriminant validity of items, multi-trait-multi-method (MT-MM) matrix analysis was performed.

(6) Pearson's correlation coefficient was used to examine the criterion-related validity with selfcompassion and GICC.

\section{Results}

\subsection{General characteristics}

Surveys from 37 males (13.9\%) and 230 females $(86.1 \%)$ were analyzed. The group comprised 85 sophomores (31.8\%), 90 juniors (33.7\%), and 92 seniors $(34.5 \%)$. Regarding religion, 119 answered yes $(44.6 \%)$ and 148 answered no (55.4\%). The number of students using SNS were $258(96.6 \%)$ and 9 did not use SNS (3.4\%). SNS user types included 192 Facebook users (71.9\%), 246 Kakao Talk users (92.2\%), and 143 Instagram users $(53.6 \%)$; this question helped rule out the duplication. Therapeutic communication course was completed by 183 students (68.5\%). Further details about the general characteristics are presented in Table 1.

\subsection{Item analysis}

To analyze the items, the average and standard deviation of the items were calculated to evaluate the item difficulty. The mean value of all 23 items ranged from 2.98 to 3.78 and did not have an extreme value centered on the intermediate score of 3 . The standard deviation ranged from 0.65 to 0.97 , and it was identified as an adequate item.

The corrected inter-item correlation of 23 items ranged from 0.23 to 0.76 . Three items with Pearson's correlation coefficients below 0.30 items number were 9,12 , and 21 .

\begin{tabular}{llr}
\hline Characteristics & Category & $N(\%)$ \\
\hline \hline Gender & Male & $37(13.9)$ \\
Grade & Female & $230(86.1)$ \\
& 3rd & $85(31.8)$ \\
Religion & 4th & $90(33.7)$ \\
& Yes & $92(34.5)$ \\
Use of SNS & No & $119(44.6)$ \\
SNS type of use* & Use & $148(55.4)$ \\
& No use & $258(96.6)$ \\
Therapeutic communication & Facebook & $9(3.4)$ \\
course completion & Kakao Talk/story & $192(71.9)^{*}$ \\
& Instagram & $246(92.2)^{*}$ \\
& Not yet received & $143(53.6)^{*}$ \\
\hline Dupleted & $183(68.5)$ \\
& Completing this semester & $29(10.9)$ \\
\hline
\end{tabular}

*Duplication answer.

Table 1. General characteristics $(N=267)$. 


\subsection{Validity}

\subsubsection{Construct validity}

The construct validity of this study was tested using EFA to assess the factor structure of the scale. The value of Kaiser-Meyer-Olkin coefficient was 0.92 and Bartlett's sphericity test, $\chi^{2}$, value was $5845.84(P<0.001)$. Thus, the results confirmed the appropriateness of the factor analysis. Factor analysis started with 23 items as the original scale. The initial EFA with a varimax rotation resulted in six factors. To use more powerful ones, three items (items no. 9, 12, and 21) with a factor loading of less than 0.40 were removed. As these 3 items were coincided with item analysis result, 20 items were analyzed by secondary factor analysis.

In the second EFA, the 20 items were divided into three factors. In all the three factors, the eigenvalue was more than 1.0 and factor loadings of 20 items were greater than 0.40 . The total variance of the explained was $63.4 \%$ (Table 2).

The first factor is compassionate conversation including eight items such as, "Let me know that I will be there if they need me." The second factor is compassionate touch including seven items such as "hold their hand" and "touch their shoulder." The third factor is compassionate messaging including five items, such as "send an email communicating compassion toward them."

The internal consistency of scale items was used with Cronbach's $\alpha$. Cronbach's $\alpha$ for internal consistency was 0.85 and the range for the three factors was from 0.71 to 0.87 (Table 2).

The three factors were positively associated with total scores. Pearson's correlation coefficients ranged from 0.55 to 0.61 , indicating an adequately moderate relationship (Table 3).

\subsubsection{Convergent validity and discriminant validity}

The convergent validity and discriminant validity of this scale was analyzed with MT-MM matrix approach. Interitems of each subscale correlation was greater than 0.40 and scaling success rate of convergent validity was $100 \%$. Inter-items of different subscales correlation were also greater than 0.40 and scaling success rate of discriminant validity was $100 \%$ (Table 4 ).

\begin{tabular}{|c|c|c|c|c|c|c|}
\hline Factor & No. & $\begin{array}{l}\text { Items } \\
\text { When a friend of mine is distressed about something } \\
\text { I tend to: }\end{array}$ & $\begin{array}{l}\text { Factor } \\
\text { loading }\end{array}$ & $\begin{array}{l}\text { Eigen } \\
\text { value }\end{array}$ & $\begin{array}{c}\text { Explained } \\
\text { variance (\%) }\end{array}$ & $\begin{array}{c}\text { Cronbach's } \\
\alpha\end{array}$ \\
\hline \multirow{8}{*}{$\begin{array}{l}\text { Compassionate } \\
\text { conversation }\end{array}$} & 16 & Try to relate to their situation & 0.80 & \multirow[t]{8}{*}{6.19} & \multirow[t]{8}{*}{31.0} & \multirow[t]{8}{*}{0.85} \\
\hline & 17 & Display interest in their issues & 0.76 & & & \\
\hline & 2 & Let them know that I will listen if they need to talk & 0.70 & & & \\
\hline & 15 & Support him or her emotionally the best I can & 0.68 & & & \\
\hline & 3 & Listen with interest when they talk & 0.65 & & & \\
\hline & 10 & Let them pour their feelings or concerns out to me & 0.63 & & & \\
\hline & 8 & $\begin{array}{l}\text { Empathize with them by trying to understand their feelings } \\
\text { or emotions }\end{array}$ & 0.60 & & & \\
\hline & 1 & Let them know that I will be there if they need me & 0.58 & & & \\
\hline \multirow[t]{7}{*}{ Compassionate touch } & 20 & Touch their back & 0.75 & \multirow[t]{7}{*}{2.65} & \multirow[t]{7}{*}{20.0} & \multirow[t]{7}{*}{0.87} \\
\hline & 4 & Touch them on their arm & 0.74 & & & \\
\hline & 6 & Touch their shoulder & 0.74 & & & \\
\hline & 18 & Rub their shoulders & 0.74 & & & \\
\hline & 19 & Put my arm around their shoulder & 0.73 & & & \\
\hline & 5 & Hold their hand & 0.68 & & & \\
\hline & 7 & Pat them on the back & 0.63 & & & \\
\hline \multirow{5}{*}{$\begin{array}{l}\text { Compassionate } \\
\text { messaging }\end{array}$} & 13 & Send a supportive email & 0.80 & \multirow[t]{5}{*}{1.84} & \multirow[t]{5}{*}{12.9} & \multirow[t]{5}{*}{0.71} \\
\hline & 14 & Send an email communicating compassion toward them & 0.74 & & & \\
\hline & 23 & Reply to their e-mails in a compassionate way & 0.63 & & & \\
\hline & 22 & $\begin{array}{l}\text { Reply to their social networking posts in a compassionate } \\
\text { way }\end{array}$ & 0.58 & & & \\
\hline & 11 & $\begin{array}{l}\text { Send them a supportive private message on their social } \\
\text { networking site (e.g., Facebook) }\end{array}$ & 0.57 & & & \\
\hline Total & & & & & 63.9 & 0.85 \\
\hline
\end{tabular}

Table 2. Factor loading from Compassionate Communication scale $(N=267)$. 


\subsubsection{Criterion-related validity}

Criterion-related validity of this scale was analyzed with correlation. The compassionate communication scale has statistically significant correlation with GICC scale $(r=0.494, P<0.001)$ and self-compassion $(r=0.317$, $P<0.001$ ) (Table 5).

\section{Discussion}

The validity and reliability of the Korean version for the Compassionate Communication Scale were examined in this study. To examine the construct validity through an EFA, a sample size of seven times number or more than 100 population was required, and the model's goodness of fit sample size was appropriated for this study. ${ }^{15}$

\begin{tabular}{lcc}
\hline & $\begin{array}{c}\text { Compassionate } \\
\text { conversation }\end{array}$ & $\begin{array}{c}\text { Compassionate } \\
\text { touch }\end{array}$ \\
\hline \hline Compassionate touch & 0.61 & - \\
Compassionate messaging & 0.55 & 0.59 \\
\hline
\end{tabular}

Table 3. Inter-subscale correlations and reliability coefficients of each subscale $(N=267)$.

\begin{tabular}{|c|c|c|c|c|}
\hline Factors & Item No. & Factor 1 & Factor 2 & Factor 3 \\
\hline \multirow{8}{*}{$\begin{array}{l}\text { Compassionate } \\
\text { conversation }\end{array}$} & 16 & 0.795 & 0.536 & 0.595 \\
\hline & 17 & 0.756 & 0.552 & 0.602 \\
\hline & 2 & 0.707 & 0.465 & 0.487 \\
\hline & 15 & 0.679 & 0.596 & 0.661 \\
\hline & 3 & 0.647 & 0.524 & 0.612 \\
\hline & 10 & 0.625 & 0.442 & 0.455 \\
\hline & 8 & 0.602 & 0.604 & 0.656 \\
\hline & 1 & 0.575 & 0.573 & 0.539 \\
\hline \multirow{7}{*}{$\begin{array}{l}\text { Compassionate } \\
\text { touch }\end{array}$} & 20 & 0.517 & 0.750 & 0.571 \\
\hline & 4 & 0.461 & 0.744 & 0.553 \\
\hline & 6 & 0.568 & 0.743 & 0.637 \\
\hline & 18 & 0.580 & 0.739 & 0.589 \\
\hline & 19 & 0.541 & 0.733 & 0.542 \\
\hline & 5 & 0.521 & 0.679 & 0.577 \\
\hline & 7 & 0.528 & 0.626 & 0.619 \\
\hline \multirow{5}{*}{$\begin{array}{l}\text { Compassionate } \\
\text { messaging }\end{array}$} & 13 & 0.504 & 0.530 & 0.873 \\
\hline & 14 & 0.589 & 0.636 & 0.864 \\
\hline & 23 & 0.572 & 0.605 & 0.668 \\
\hline & 22 & 0.571 & 0.601 & 0.509 \\
\hline & 11 & 0.575 & 0.585 & 0.445 \\
\hline
\end{tabular}

Note: Bold values: subscale correlation of greater than 0.40 .

Table 4. Multi-trait multi-item matrix for convergent and discriminant validity
The original scale was developed as 65 items at first and then three pilot studies were performed to verify it. It was finally classified into 23 items and 3 factors.

In all, 23 items of the original scale were analyzed in this study, 20 items and 3 subscales which 3 items were extracted came out as the result. The results of factor analysis showed three factors, such as compassionate conversation, compassionate touch, and compassionate messaging. This result was similar to the original scale. The three extracted items were statistically verified by item analysis and the number of items was the same as one result by construct validity. This means that stability and reliability were adequate.

After removing three items, the final EFA derived from three factors with eigenvalues greater than 1.0. Total factor accounted for $63.9 \%$ and it was concluded that it was higher than the total variance of the original version $(54.26 \%)$. The explained variance from $50 \%$ to $60 \%$ means high contribution and significance to the factor. ${ }^{19}$ After extracting three items, this scale showed that the total explained variance and the variance of three factors were higher than the original scale. In addition, all the factor loadings of items were greater than 0.5 in this study; the higher the factor loading was, the more statistically significant the result was. This scale met acceptable criteria on the total variance, the eigenvalue,$^{20}$ and the major dimensions of compassionate communication were well reflected. Thus, this scale can be considered as a useful measurement.

To determine whether the subscale has a unique property, the correlation coefficients of each subscale were lower than Cronbach's a coefficient among each subscale. ${ }^{21}$ That is, this study identified the correlation coefficients between subscales ranging from 0.55 to 0.61 and each subscale's Cronbach's a ranged from 0.71 to 0.87 . And then, Cronbach's $\alpha$ of the total items was 0.85 . It means that this scale confirmed acceptability and had sound internal consistency and reliability. ${ }^{22}$ Therefore, each subscale's properties were determined.

To examine the convergent and discriminant validity, MT-MM was approached in this study. A matrix was used to examine the relationship of each item. ${ }^{23}$ Convergent validity shows inter-correlation of the subscale's items, whereas discriminate validity shows the association between the other subscales' items, compared with and its ones. ${ }^{24}$ In this study, correlation coefficients of

\begin{tabular}{lcc}
\hline Variables & Self-compassion $r(P)$ & GICC $r(P)$ \\
\hline \hline $\begin{array}{l}\text { Compassionate } \\
\text { communication }\end{array}$ & $0.317(P<0.001)$ & $0.494(P<0.001)$ \\
GICC & $0.313(P<0.001)$ & - \\
\hline
\end{tabular}

Table 5. Correlations among all variables $(N=267)$. 
inter-item of subscales showed at least 0.40 , and the convergent validity approached $100 \%$ completely. Each other subscale's item correlation coefficient was greater than 0.40 , and the discriminant validity also approached a $100 \%$ scaling success rate. ${ }^{23}$ Therefore, this subscale was identified as an independent set.

Factor 1, compassionate conversation accounted for $31.0 \%$ of the variance, reflected the highest explained variance. This factor was also as high as the original version $(28.52 \%)^{4}$ was. Compassionate conversation including eight items such as "Let them know that I will listen if they need to talk" and "Emphasize with them by trying to understand their feelings or emotions." This factor emphasized "empathy" for others. In other words, this factor represented the attitude for empathy with another person who faced difficulty. As the attitude affects communication and the core of compassionate conversation, this factor should have a high explanation associated with variance. Extracted items included "Express sympathy toward their situation," in this factor (compassionate conversation). It may affect the education about "sympathy" definition in the course of communication. Nursing educators tended to educate empathy because sympathy has a negative meaning such as, "pity" or "poor."

Factor 2 known as compassionate touch accounted for $20 \%$ of the explained variance, and it was a little higher than $16.32 \%$ of the original version. The number of this factor items is the same as the original version. This factor, compassionate touch, involves using tactile behaviors, which related to communication comfort and social bonding in the relationships. ${ }^{4}$ Compassionate touch included seven items which represented empathy as expressing through contact, such as "touch them on their arm," "pat them on the back," and "rub their shoulders." Although little research has investigated tactile communication, a touch is a key behavior used for communication comfort and social support. ${ }^{4}$ This factor can measure non-verbal communication, and it may be an important behavior of the compassionate communication.

Factor 3, the compassionate messaging, took up $12 \%$ of the explained variance. The original version was $9.43 \%$ among three factors. Both the original version and this scale were the lowest. This factor consisted of communication on SNSs, such as "Send them a supportive private message on their social networking site (e.g., Facebook)" or "Send an email communicating compassion toward them." This factor can measure digital communication. However, this factor extracted two items, which were, "post a positive message on their social networking site (e.g., Facebook)" and "post a compassionate message on their social networking site (e.g., Facebook)." Two items have the same word, "post." In these items, "post" means an open attitude in such supporting message as Facebook. SNSs communication activities had significant differences between the United States and the East Asia countries, such as South Korea and China, which were influenced by Confucian culture..$^{13}$ This result shows that traditional Korean culture is reluctant to open-mind behavior. An example of this would be the posting supportive messages on Facebook. Thus, this result needs to be repeated for a study of cultural validity. To confirm the cultural suitability and ease of understanding, the developmental scale of translation research must have backward translation for mutual independent process. ${ }^{22}$ Improving the construct validity following repeated study with similar population needs to be performed..$^{23}$ In conclusion, based on our investigations, we recommend that further study should confirm the impact of Confucian culture in East Asia.

Criterion-related validity measures how well one measure predicts an outcome for another measure, and the criterion variables might be any established standard of the phenomenon of interest. ${ }^{22}$ To examine the criterion-related validity, this study selected two variables of the self-compassion and GICC because these scales related concepts to compassion and communication. The Compassionate Communication Scale scores were positive and significant since they correlated with the self-compassion and GICC scores. Therefore, the Compassionate Communication Scale was conceptually associated with self-compassion and GICC.

\section{Conclusions}

Measurements are very essential for research. If they possess inappropriate statistical properties included in nursing research, it can threaten the reliability of the study's results. ${ }^{15,24}$ For sound validity and reliability, one should employ appropriate statistical methods. However, developing psychometric measurements is difficult because they have insufficient evidence. ${ }^{22}$ Despite these challenges, researchers should continue to develop psychometric measurements.

Many researchers suggested that to measure quality psychometric properties, they should apply advanced statistics, such as construct validity, MT-MM, and criterion validity. ${ }^{23,25}$ According to this study, once these advanced methods are applied to statistics, validity and reliability can be better. The result of this study showed that validity and reliability could be satisfied when this study was performed as the advanced statistics. Thus, this scale could be used in evaluating communication ability in nursing education and the field where therapeutic communication occurs. It should be especially appropriate to measure compassionate communication, including all SNS users. 
This study had limitations owing to the fact that those who participated in the study were students from just two universities. Future study with a larger sample size might re-assess compassionate communication ability. After removing three items of this scale, the explained variance was higher than the original version. Thus, there is a need to re-test this scale to identify through the further research.

\section{Acknowledgment}

This paper was supported by Jeonju University in 2018.

\section{Ethics approval}

This study was approved by J University's Institutional Review Board (Approval No. jjlRB-170417- HR-20170413). All participants were informed that if they do not want to participate at any point during the study, they could withdraw from participation. Written informed consent was obtained from all the participants.

\section{Conflicts of interest}

All contributing authors declare no conflicts of interest.

\section{References}

1. Williams $\mathrm{KN}$, Boyle DK, Herman RE, Coleman CK, Hummert ML. Psychometric analysis of the emotional tone rating scale: a measure of person-centered communication. Clin Gerontol. 2012;35:376-398.

2. Kim BN, Kim SO. A study on assessment system for Nursing Bachelor Degree Program outcomes focused on communication ability improvement. J Korean Acad Nurs Adm. 2014;20:154-166 (in Korean).

3. Lee HY, Oh KS, Ahn YH, Lee SJ, Kim IJ. Exploratory study on scales of nursing education outcome. J East-West Nurs Res. 2010;16:53-60 (in Korean).

4. Ramos Salazar L. Communicating with Compassion: The Exploratory Factor Analysis and Primary Validation Process of the Compassionate Communication Scale. Arizona State University; 2013.

5. McElroy C, Esterhuizen P. Compassionate communication in acute healthcare: establishing the face content validity of questionnaire. $J$ Res Nurs. 2017;22:72-88.

6. Neff KD. Development and validation of a scale to measure self-compassion. Self Identity. 2003;2:223-250.

7. Huffman TP. Compassionate communication embodied aboutness, and homeless young adults. West J Commun. 2016;81:149-167.

8. Dewar B, Nolan M. Caring about caring: developing a model to implement compassionate relationship centered care in an older people care setting. Int J Nurs Stud. 2013;50:1247-1258.

9. Ledoux K. Understanding compassion fatigue: understanding compassion. J Adv Nurs. 2015 71:2041-2050.

10. Winch S, Henderson A, Jones J. Recognizing the dialectic of compassionate care in the workplace: feedback from nurse educators. J Contin Educ Nurs. 2015;46:228-232.
11. Dewar B, Adamson E, Smith S, Surfleet J, King L. Clarifying misconceptions about compassionate care. J Adv Nurs. 2013;70:1738-1747.

12. Jones J, Sarah W, Strube P, Mitchee M, Hendeson A. Delivering compassionate care in intensive care units: nurses' perceptions of enablers and barriers. J Adv Nurs. 2016;72:3137-3146.

13. Ji YG, Hwangbo H, Yi JS, Rau P, Fang X, Ling C. The influence of cultural differences on the use of social network services and the formation of social capital. Int J Hum Comput Interact, 2010;26:1100-1121.

14. Park SY, Cha SB, Lim K, Jung SH. The relationship between university student learning outcomesand participation in social networkservices, social acceptance and attitude towards school life. Br J Educ Technol. 2014;45:97-111.

15. Terwee CB, Mokkink LB, Knol DL, Ostelo RW, Bouter LM, de Vet HC. Rating the methodological quality in systematic reviews of studies on measurement properties: a scoring system for the COSMIN checklist. Qual Life Res. 2012;21:651-657.

16. Jin HJ, Lee KH. The validation of the Korean version of self-compassion scale. J Youth Couns. 2009;17:1-20 (in Korean).

17. Hur $\mathrm{KH}$. Construction and validation of a global interpersonal communication competence scale. Korean J Journal Commun Stud. 2003;47:380-408 (in Korean).

18. Rubin RB, Matin MM, Bruning SS, Power DE. Interpersonal communication competence: scale development and test of a self-efficacy model. Atlanta, GA: Paper presented meeting of the Communication Association; 1991.

19. Kang HC. A guide on the use of factor analysis in the assessment of construct validity. J Korean Acad Nurs. 2003;587-594 (in Korean). 
20. Munro BH. Statistical Methods for Health Care Research. 5th ed. Philadelphia, PA: Lippincott Williams \& Wilkins;2005.

21. Ware JE, Gandek B. Methods for testing data quality, scaling assumptions, and reliability: The IQOLA project approach. J Clin Epidemiol. 1998;51:945-952.

22. Lee EH, Kim CJ, Kim EJ, Chae HJ, Cho SY. Measurement properties of Self-report Questionnaires Published in Korean Nursing. J Korean Acad Nurs. 2013;43:50-58 (in Korean).
23. DeVon HA, Block ME, Moyle-Wright P, et al. A psychometric toolbox for testing validity and reliability. J Nurs Scholarsh. 2007;39:155-164.

24. Fayers PM, Machin D. Quality of Life: The Assessment, Analysis and Reporting of Patient-Reported Outcomes. 3rd ed. Chichester, UK: John Wiley \& Sons; 2016.

25. Mokkink IB, Terwee CB, Patrick DI, et al. The COSMIN study reached international consensus on taxonomy, terminology and definitions of measurement properties for health-related patient-reported outcomes. J Clin Epidemiol. 2010;63:737-745. 